\title{
Micropermeability in Cementing Fiber Posts with Self-Adhesive Cement - Influence of the Surface Treatment
}

\author{
Sevda Yantcheva ${ }^{1 *}$, Silvia Dimitrova ${ }^{2}$ and Radosveta Vasileva ${ }^{3}$ \\ ${ }^{1}$ Chief Assistant, Department of Conservative Dentistry, Medical University, Bulgaria \\ ${ }^{2}$ Former Assistant, Department of Conservative Dentistry, Medical University, Bulgaria \\ ${ }^{3}$ Chairman and Professor, Department of Conservative Dentistry, Medical University, Bulgaria
}

Submission: December 21, 2020; Published: January 04, 2021

*Corresponding author: Sevda Yantcheva, Department of Conservative Dentistry, Faculty of Dental Medicine, Medical University, Sofia, Bulgaria

Keywords: Hydrofluoric acid; Hydrogen peroxide; Orthophosphoric acid; Maxcem Elite double-polymerizing; Micropenetration

\section{Introduction}

Over the last decade, fiber posts have been increasingly used to restore severely damaged, endodontically treated teeth [1-5]. They have become popular as an alternative to metal posts due to their aesthetics and biomimetic behavior, bringing them closer to the properties of the natural dentin [6-8]. By themselves, radicular posts cannot connect to the root canal dentin. This connection is mediated by the cement. The aim is for the cement to provide a tight seal of the endodontic space, to completely prevent micropenetration, to support the formation of a monoblock between the root canal dentin, the cement and the fiber post $[3,6,9,10]$. One of the main problems with the fiber posts is the loss of retention leading to detachment $[3,7,11,12]$. There are two factors that need to be worked on. One is related to the surface treatment of the fiber post surface, which is necessary due to the highly crosslinked epoxy matrix of most types of fiber posts $[6,3,13]$.

A retention surface with exposed glass fibers is required to bond to the adhesive systems and the composite cements. The second factor influencing the longevity of recovery is the relationship with the root canal dentin. The problems stem from the high C-factor in the range of the root canal space $[14,15]$; the thick smear layer formed during the post placement preparation [1618]; the nature of the root canal dentin; the continuous deposition of secondary dentin and cement $[4,10,16]$. In this regard, easyto-use methods are required that do not need special equipment for surface treatment of the post surface in combination with a reliable and shorter adhesive protocol, which will ensure the formation of a complete uniform structure between the fiber post, composite cement and root canal dentin. The aim of the present in vitro study is to investigate the level of micropermeability along fiber posts pre-treated with $\mathrm{HF}$ (hydrofluoric acid), $\mathrm{H}_{2} \mathrm{O}_{2}$ (hydrogen peroxide), $\mathrm{H}_{3} \mathrm{PO}_{4}$ (orthophosphoric acid) and bonded with self-adhesive cement.

\section{Material and Methods}

80 single-rooted extracted teeth were used in the study, which did not undergo endodontic treatment. Until their use for the experiment, the teeth were stored in a $10 \%$ solution of formalin. After transverse cross-section of the teeth $2 \mathrm{~mm}$ above the cementoenamel junction with a diamond bur and waterair cooling, endodontic treatment was performed. A step back technique was used for root canal preparation. The apical stop was made using a No. 40 K-file, after which a series of steps back were performed to reach a No. 80 K-file (VDW Dental, Germany). After each file, $5,25 \%$ sodium hypochlorite $(2 \mathrm{ml})$ and $3 \%$ hydrogen peroxide $(2 \mathrm{ml})$ were used for irrigation. The final irrigation was done with saline $(4 \mathrm{ml})$. The canals were dried with paper points (VDW Dental, Germany) and filled by the method of cold lateral condensation with gutta-percha points (VDW Dental, Germany) and Seal apex (Kerr Hawe) sealer. After filling the canals, the teeth were left for 24 hours in isotonic saline at room temperature.

Dentin Posts - Komet Dental - size2, corresponding - ISO 90; taper angle 2 degrees were selected for the experiment.

The root canals were widened with a low-speed handpiece and standardized drills for the Dentin Posts (Komet Dental) 
system at a depth of $8 \mathrm{~mm}$. After preparation, the canals were irrigated with $5.25 \%$ sodium hypochlorite $(2 \mathrm{ml})$ and saline $(4 \mathrm{ml})$. They were dried using an air jet and paper points. Before being cemented, the fiber posts were subjected to a preliminary surface treatment, on the basis of which they were divided into 8 groups.

\section{a) Group 1: HF 5\% (60sec) + silane (60sec)}

The posts were covered with HF $5 \%$ for 60 sec. They were washed using a water-air jet for $60 \mathrm{sec}$ and were dried using an air jet. Silane was applied in a thin layer according to the instructions for use. After $60 \mathrm{sec}$, residual moisture was removed using an air jet

\section{b) Group 2: HF 5\% (60sec)}

The posts were covered with HF $5 \%$ for 60 sec. They were washed using a water-air jet for 60 sec and were dried using an air jet.

\section{c) Group 3: $\mathrm{H}_{2} \mathrm{O}_{2} 30 \%(10 \mathrm{~min})+$ silane $(60 \mathrm{sec})$}

The posts were submerged in $\mathrm{H}_{2} \mathrm{O}_{2} 30 \%$ for $10 \mathrm{~min}$. They were taken out and dried using an air jet. Silane was applied in a thin layer according to the instructions for use. After $60 \mathrm{sec}$, residual moisture was removed using an air jet.

\section{d) Group 4: $\mathrm{H}_{2} \mathrm{O}_{2} 30 \%(10 \mathrm{~min})$}

The posts were submerged in $\mathrm{H}_{2} \mathrm{O}_{2} 30 \%$ for $10 \mathrm{~min}$. They were taken out and dried using an air jet.

\section{e) Group 5: $\mathrm{H}_{3} \mathrm{PO}_{4} 37 \%(60 \mathrm{sec})+$ silane $(60 \mathrm{sec})$}

The posts were covered with $\mathrm{H}_{3} \mathrm{PO}_{4} 37 \%$ for $60 \mathrm{sec}$. They were washed using a water-air jet for $60 \mathrm{sec}$ and were dried using an air jet. Silane was applied in a thin layer according to the instructions for use. After $60 \mathrm{sec}$, residual moisture was removed using an air jet

\section{f) Group 6: $\mathrm{H}_{3} \mathrm{PO}_{4} 37 \%$}

The posts were covered with $\mathrm{H}_{3} \mathrm{PO}_{4} 37 \%$ for 60 sec. They were washed using a water-air jet for $60 \mathrm{sec}$ and were dried using an air jet.

\section{g) Group 7: Silane (60sec)}

The posts were cleaned with a cotton ball and 75\% alcohol. They were dried using an air jet. Silane was applied directly in a thin layer according to the instructions for use. After $60 \mathrm{sec}$, residual moisture was removed using an air jet.

\section{h) Group 8: Saline solution - control group (60sec)}

The posts were dipped in saline for 60sec. They were taken out and dried using an air jet.

After surface treatment of the posts, 1 post was taken out of each group for SEM monitoring and evaluation of the surface. Thus, 10 processed posts remain to participate in the experiment, which corresponds to the number of prepared teeth.

The SEM analysis was done after coating the specimens with gold by cathodic sputtering under low vacuum (JEOL JFC-1200/ JEOL JSM-5510). All 80 fiber posts were cemented with Maxcem Elite double-polymerizing self-adhesive cement (Kerr / Hawe). The cement was applied directly to the posts using the cannulas of the mixing nozzles. The posts were placed slowly with light pressure in the prepared canals, the excess cement was removed and photopolymerization was done for $20 \mathrm{sec}\left(1200 \mathrm{~mW} / \mathrm{cm}^{2}\right.$; Elipar Freelight 2.3M ESPE) with the flat surface of the light guide resting on the crown part of the post. Table 1 shows the main materials used in the study.

Table 1: Main materials used in the study.

\begin{tabular}{|c|c|c|}
\hline Material & Manufacturer & Composition \\
\hline Fiber post & $\begin{array}{c}\text { Komet Dental } \\
\text { Dentin post }\end{array}$ & $\begin{array}{c}\text { Matrix: epoxy } \\
\text { Fibers: Fiber Glass 60\% }\end{array}$ \\
\hline Silane & $\begin{array}{c}\text { Monobond plus (Viva- } \\
\text { dent Ivoclar) }\end{array}$ & silane methacrylate, phosphoric methacrylate, sulfide methacrylate. \\
\hline $\begin{array}{c}\text { Self-adhesive } \\
\text { cement }\end{array}$ & $\begin{array}{c}\text { Maxcem Elite } \\
\text { (Kerr Hawe) }\end{array}$ & $\begin{array}{c}\text { Barium aluminoborosilicate glass; Ytterbium fluoride; 1,6-hexanediyl bismethacrylate; 2-hydroxy-1,3-pro- } \\
\text { panediyl bismethacrylate; 7,7,9 } \text { (or 7,9,9)-trimethyl-4,13-dioxo-3,14- dioxa-5,12-diazahexadecane-1,16-di- } \\
\text { yl bismethacrylate; 3-trimethoxysilylpropyl methacrylate; Fumed silica }\end{array}$ \\
\hline
\end{tabular}

The specimens were stored for 24 hours at room temperature, after which the apexes of all teeth were sealed with adhesive wax. All specimens were varnished with 2 coats of nail polish, except for a limited area of $1 \mathrm{~mm}$ around the fiber post. The specimens thus prepared were immersed in a $2 \%$ solution of methylene blue for 24 hours. They were then washed under running water and cut longitudinally in the middle using a diamond separator. Both halves were smoothed with finishing discs (Soflex-3M ESPE). The degree of penetration of the dye was measured using magnifying glasses ( $\mathrm{x} 4$ ). The penetration values of the dye were reported in $\mathrm{mm}$, and for each specimen the value of the deepest penetration in the direction of the apical zone was recorded. The results of the study were statistically processed. The following methods were used.

\section{Descriptive methods}

Methods appropriate to standard deviation, median, minimum and maximum value were used to describe the data. The results were given with accuracy up to the second decimal place.

\section{Methods of statistical conclusion}

A dispersion analysis was used to check hypotheses regarding the means. The classification of the groups was performed by the LSD (least significant difference) method and confirmed by the classification of the average ranks. 
Results

Table 2: Basic descriptive statistics by groups.

\begin{tabular}{|c|c|c|c|c|c|c|c|}
\hline \multicolumn{2}{|c|}{ Group } & \multicolumn{6}{|c|}{ Value } \\
\hline & & \multirow{2}{*}{$\frac{\mathbf{N}}{10}$} & \multirow{2}{*}{$\begin{array}{c}\text { mean } \\
, 91 \\
\end{array}$} & \multirow{2}{*}{$\begin{array}{l}\text { sd } \\
18\end{array}$} & \multirow{2}{*}{$\begin{array}{c}\text { med } \\
90\end{array}$} & \multirow{2}{*}{$\begin{array}{l}\max \\
1,20\end{array}$} & \multirow{2}{*}{$\begin{array}{r}\text { min } \\
60\end{array}$} \\
\hline Group I: HF $5 \%+$ silane & Maxcem Elite & & & & & & \\
\hline Group II: HF 5 \% & Maxcem Elite & 10 & ,71 & ,36 &, 70 & 1,50 & ,20 \\
\hline Group III: $30 \% \mathrm{H}_{2} \mathrm{O}_{2}+$ silane & Maxcem Elite & 10 & ,33 & ,17 &, 40 & ,60 & 10 \\
\hline Group IV: $30 \% \mathrm{H}_{2} \mathrm{O}_{2}$ & Maxcem Elite & 10 &, 57 &, 51 &, 40 & 1,80 & 10 \\
\hline Group V: $37 \% \mathrm{H}_{3} \mathrm{PO}_{4}+$ silane & Maxcem Elite & 10 & ,74 & ,21 & ,80 & 1,10 &, 50 \\
\hline Group VI: $37 \% \mathrm{H}_{3} \mathrm{PO}_{4}$ & Maxcem Elite & 10 & 81 & 16 & 80 & 1,00 &, 50 \\
\hline Group VII: SILANE & Maxcem Elite & 10 & ,60 & ,12 & ,60 &, 80 & 40 \\
\hline Group VIII: $\mathrm{NaCl} 0.9$ \% & Maxcem Elite & 10 & 7,20 & 1,03 & 8,00 & 8,00 & 6,00 \\
\hline
\end{tabular}

Table 2 summarizes the results of the study, after statistical processing to the second decimal place. In all main groups, regardless of the surface treatment, we register the presence of micropermeability. In Table 3, the individual groups are arranged in descending order according to the obtained average values of micropermeability.

Table 3: Comparison between groups by means.

\begin{tabular}{|c|c|c|c|c|}
\hline \multicolumn{7}{|c|}{ Mean values with different superscripted letters are significantly different (p < 05) } \\
\hline \multicolumn{2}{|c|}{ Grouping } & Mean* & N & Group \\
\hline & a & 7.2 & 10 & 8 \\
\hline & b &, 91 & 20 & 6 \\
\hline c & b &, 81 & 20 & 5 \\
\hline b & c &, 74 & 20 & 2 \\
\hline d & c &, 71 & 20 & 7 \\
\hline d & c &, 60 & 20 & 4 \\
\hline d & c &, 57 & 20 & 3 \\
\hline
\end{tabular}

The lowest penetration was in group III: $30 \% \mathrm{H}_{2} \mathrm{O}_{2}+$ silane, and the highest values were registered in control group VIII: $\mathrm{NaCl} 0.9 \%$. Figure $1(\mathrm{~A}-\mathrm{E})$ presented CEM images reflecting the condition of the post surface after the different types of surface treatment. When analyzing the scanning electron microscope images, it became clear that the surface treatment with HF 5\% leads to superficial dissolution of the matrix and revealing the fibers of the posts. However, the exposed fibers have a damaged structure. Both longitudinal and transverse cracks and fractures were observed (Figure 1A). Surface stripping of the fibers of the pins from the surrounding matrix is also observed during treatment with $\mathrm{H}_{2} \mathrm{O}_{2} 30 \%$, there are no damages in the structural integrity of the fibers (Figure 1B). Treatment with $\mathrm{H}_{3} \mathrm{PO}_{4} 37 \%$ leads to dissolution of the matrix around the superficial fibers, on the exposed fibers there are clear traces of undissolved matrix (Figure 1C). The application of silane on the fiber posts leads to the formation of a homogeneous film on them, which prevents the visualization of the treated surface (Figure 1D). The control group treated only with saline showed exposed single fibers covered with traces of matrix. There are no disturbances in the surface structure of the posts (Figure 1E).

\section{Discussion}

When fixing the fiber posts, the aim is to form a monoblock including the post, the composite cement and the root canal dentin $[3,6,9]$. The hermetic connection between different materials and structures is still an unsolved problem in modern adhesive dentistry. Boundary surfaces are areas where micropermeability can occur. To prevent this phenomenon, work is done in the direction of appropriate conditioning of the fiber-post surface on the one hand and on the other, on the selection of a means for a reliable adhesive bond with the root canal dentin. It is essential for the clinic practice that the offered work techniques are accessible, easy to implement, and at the same time lead to reliable results. For this reason, self-adhesive cement was used in the present study to fix the posts. The self-adhesive cements were created in 2002 in order to simplify the fixing of indirect restorations, including radicular posts. The adhesive protocol reduces the risk of errors no etching, rinsing, application of adhesive system is required. The data in the literature about them are contradictory. Some authors indicate better results of the adhesive bond obtained by fixing with self-adhesive cements, compared to composite cements with 
IV, V and VI generation adhesive systems $[8,19]$. Other studies have shown a significantly higher bond strength when bonding fiber posts with a composite cement and a generation IV adhesive system than with self-adhesive cement [20-22].

In the present study, we recorded micropermeability of the dye in all experimental groups. This cannot be attributed to or compensated for solely by the connection of the self-adhesive cement to the root dentin. The connection of the fiber post with the cement is essential. The matrix of most fiber posts is epoxy based, less often methacrylate. It is highly crosslinked and has a high conversion rate $[3,6,10]$. The matrix of the posts we used is also epoxy. This gives the posts greater resistance to pressure and stress [9]. The epoxy matrix cannot chemically bond to the methacrylate groups of the composite cement or adhesive system. We can count on a micromechanical connection with the irregularities on the post surface [23,24]. After the CEM analysis of the fiber post surface, treated only with physiological solution (Figure 1D), we can find that it is not rough enough to allow the creation of a quality micromechanical connection. Evidence of this is the registered highest level of microleakage reported in the control group. The difference is statistically significant compared to the experimental groups in which the surface treatment of the posts was done. This supports the scientific views on the need for additional treatment of the fiber post surface [14, 23,25]. Hydrofluoric acid, hydrogen peroxide and phosphoric acid are substances that dissolve the epoxy matrix and can reveal the glass fibers included in the matrix. They are known in dental practice and are easily applicable in clinical conditions. Hydrofluoric acid is routinely used to condition ceramic structures and improve their bonding to hard dental tissues through cementation. Studies on its effect on the fiber post surface are contradictory.

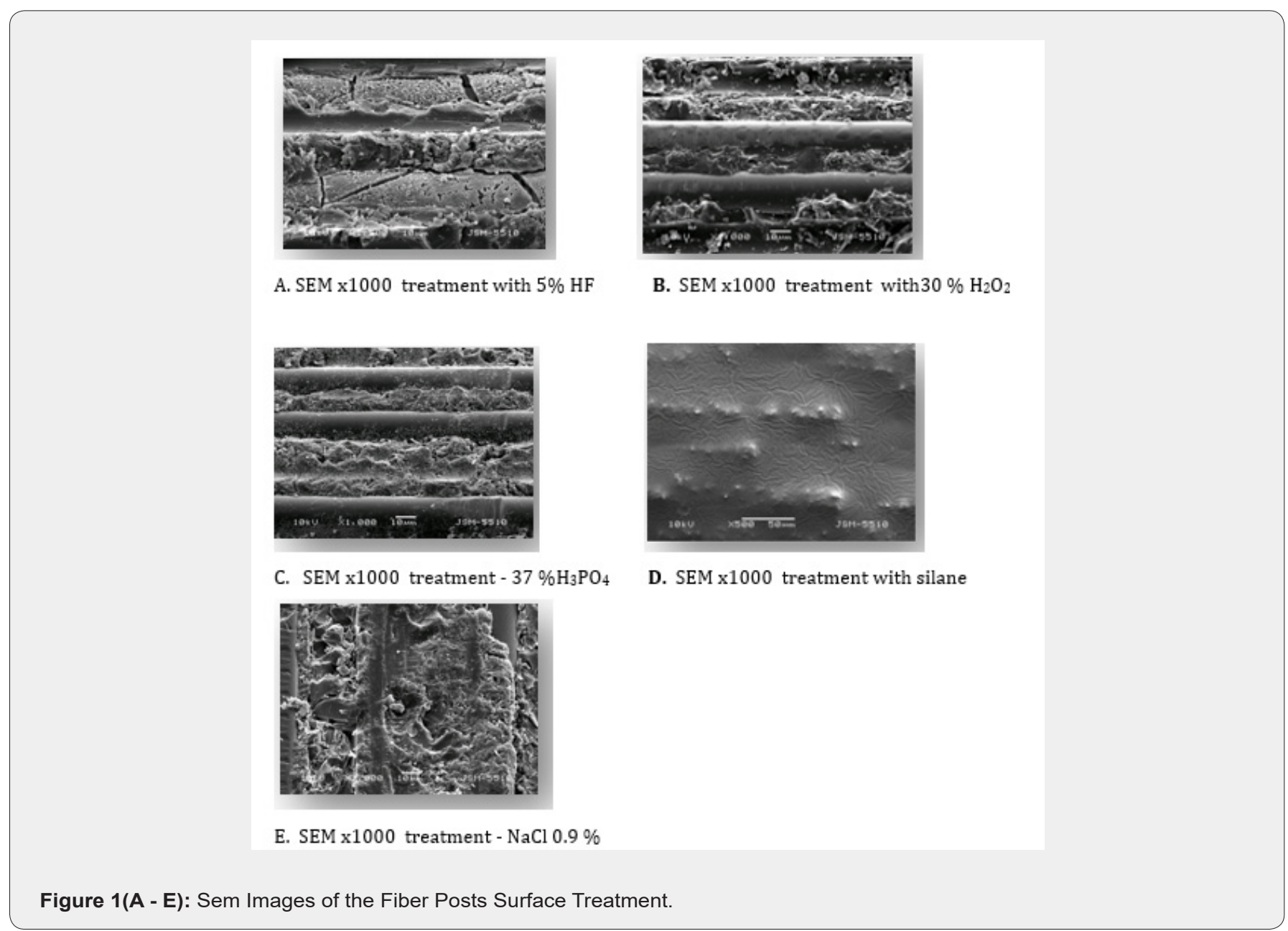

According to most researchers, the effect of $\mathrm{HF}$ is too aggressive, disrupts the integrity of the glass fibers, does not improve the adhesive bond to the cement and adversely affects the physicochemical properties of the posts, disrupts the coherence between the prepared canal and the post $[16,17,24]$. From the
CEM examination (Figure 1A) many exposed fibers can be seen, among the dissolved epoxy matrix, which have longitudinal and transverse cracks. The micropermeability in the group of HF5\% (with and without silane) is significantly higher, compared to the group in which the treatment was done with $\mathrm{H}_{2} \mathrm{O}_{2} 30 \%$, but 
still significantly less than that of the control group. The surface looks dry. Silanization of this surface does not reduce the level of micropermeability, on the contrary (Table 3 ). The obtained results give us reason to believe that the surface treatment of fiber posts with hydrofluoric acid should be avoided in clinical practice, as it hides more risks than benefits.

The etching effect of $\mathrm{H}_{2} \mathrm{O}_{2}$ is determined by its ability to partially dissolve the epoxy matrix by breaking the epoxy bonds through the oxidation mechanism $[23,25]$. The effect of $\mathrm{H}_{2} \mathrm{O}_{2}$ is selective - it does not damage the glass fibers, which is evident from the scans (Figure 1B). The spaces that are created are a condition for making a micromechanical connection with the adhesive material, while the exposed glass fibers increase the possibility of chemical bonding by silanization to composite materials [26]. The lowest level of micropenetration is registered in a group received surface treatment with $\mathrm{H}_{2} \mathrm{O}_{2} 30 \%$ and silane. Opinions in the literature on silanization are controversial. According to an extensive metaanalysis of in vitro studies [27], silanization has a positive effect on the strength of fiber posts bonding in studies performed on extracted teeth, whereas in studies performed on models, it does not play a role in improving the connection with fiber posts. Silanes are bifunctional substances that bind organic to inorganic substances. They react with the silicates of the fiber-post fibers and polymerize with the methacrylate groups of the adhesive, thus the bond between the post surface and the cementing agent is chemical [13]. In the present study, the groups with silanization performed after surface treatment of the posts did not differed statistically compared to the groups without silanization. The only group that stood out significantly after silanization was that of $\mathrm{H}_{2} \mathrm{O}_{2}$.

According to phosphoric acid - it does not lead to clear disclosure of glass fibers; they remain discreetly covered by a matrix. The microspaces in the matrix are not so distinct and retentive if we look at the CEM images (Figure 1B). According to some researchers, phosphoric acid leads only to mechanical cleaning of the post surface, without altering it at all and increasing its binding capacity [3]. We cannot completely agree with them, as we see changes on the post surface, there is a statistical decrease in micropermeability compared to the control group. But in fact, the effect is not as pronounced as after treatment with $\mathrm{H}_{2} \mathrm{O}_{2} 30 \%$, providing a cleaner reactive surface.

\section{Conclusion}

Based on the results obtained and within the limitations of in vitro studies, the following can be concluded:

i. The surface treatment of the posts with $30 \%$ hydrogen peroxide makes the pin surface more retentive, dissolving the epoxy matrix without damaging the exposed glass fibers.

ii. The lowest micropermeability when fixing fiber posts with self-adhesive cement is established after surface treatment with $\mathrm{H}_{2} \mathrm{O}_{2} 30 \%$ and the next step of silanization.

The surface treatment of fiber posts with hydrofluoric acid should be avoided in clinical practice as it carries more risks than benefits.

\section{References}

1. Ferrari M, Ferrari M, Breschi L, Grandini S (2008) Fiber posts and endodonically treated teeth: a compendium of scientific and clinical perspectives. Wendywood: Modern Dentistry Media 2008, pp. 9-13.

2. Jung SH, Min KS, Chang HS, Park SD, Kwon SN, et al. (2007) Microleakage and fracture patterns of teeth restored with different posts under dynamic loading. J Prosthet Dent 98(4): 270-276.

3. Machado AC, Vilela ALR, Souza PG (2014) Critical analysis of fiber post surface treatment: A review. Biosci J Uberlandia 30(3): 914-924.

4. Makarewicz D, Le Bell-Rönnlöf A-M, Lassila L, Vallittu P (2013) Effect of Cementation Technique of Individually Formed Fiber-Reinforced Composite Post on Bond Strength and Microleakage. The Open Dentistry Journal 7: 68-75.

5. Sarkis Onofre R, Pinheiro HA, Poletto Neto V (2020) Randomized controlled trial comparing glass fiber posts and cast metal posts. Journal of Dentistry 96: 103334.

6. Goracci C, Ferrari M (2011) Current perspectives on post systems: a literature review. Aust Dent J 56 (1): 77-83.

7. Schmage P, Cakir FY, Nergiz I, Pfeiffer P (2009) Effect of surface conditioning on the retentive bond strength of fiber-reinforced composite posts. The Journal of Prosthetic Dentistry 102(6): 368-377.

8. Zbou L, Wang Q (2013) Comparison of fracture resistance between cast posts and fiber posts. JOE 39(1): 11-15.

9. Lamichhane A, Xu Chun, Lhang F (2014) Dental fiber-post resin base material: a review. J Advanced Prosthodont 6(1): 60-65.

10. Machado J, Almeida P, Fernandes S, Marques A, Vaz M (2017) Currently used systems of dental posts for endodontic treatment. $2^{\text {nd }}$ International Conference on Structural Integrity, ICSI 2017, 4-7 Funchal, Madeira, Portugal. Procedia Structural Integrity 5: 27-33.

11. Balbosh A, Kern M (2006) Effect of surface treatment on retention of glass-fiber endodontic posts. J Prosthet Dent 95(3): 218-223.

12. Dietchi D, Duc O, Krejci I, Sadan A (2008) Biomechanical considerations for the restoration of endodontically treated teeth: a systematic review of the literature. Part II (Evaluation of fatigue behavior, interfaces, and in vivo studies). Quintessence Int 39(2): 117-129.

13. Monticelli F, Ferrari M, Toledano M (2008) Cement system and surface treatment selection for fiber post luting. Med Oral Patol Oral Cir Bucal 13(3): E214-E221.

14. Mishra L, Khan AS, Velo MMAC, Panda S, Zavattini A, et al. (2020) Effects of Surface Treatments of Glass Fiber-Reinforced Post on Bond Strength to Root Dentine: A Systematic Review. Materials 13(8): 1967.

15. Tay F, Lousbinen RJ, Lambrechts P, Weller RN, Pashley DH (2005) Geometric factor affecting dentine bonding in root canals: A theorethicalmodelling approach. J Endodont 31(8): 564-88.

16. Bitter K, Perdigao J, Hartwig Ch, Neumann K, Kielbassa A (2011) Nanoleakage of Luting Agents for Bonding Fiber Posts After Thermomechanical Fatigue. J Adhes Dent 13(1): 61-69.

17. Oliveira SSA, Pugach MK, Hilton JF, Watanabe LG, Marshall SJ, et al. (2003) The influence of the dentin smear layer on adhesion: a selfetching primer vs. a total-etch system. Dent Mater 19(18): 758-767. 
18. Tay FR, Sano H, Carvalho RM, Pashley DH (2000) Effect of smear layers on bonding of a self-etching primer to dentin. J Dent Res 79: 356-356.

19. Prado M, Marques JN, Pereira GD, da Silva EM, Simao RA (2017) Evaluation of different surface treatments on fiber post cemented with a self - adhesive system. Materials Science and Engineering C77: 257 262.

20. Valandro LF, Yoshiga S, de Melo RM (2006) Microtensile bond strength between a quartz fiber posts and a resin cement: effect of post surface conditioning. The Journal of Adhesive Dentistry 8 (2): 105-111.

21. Mazzoni A, Marchesi G, Cadenaro M, Mazzotti G, Di Lenarda R, et al. (2009) Push-out stress for fibre posts luted using different adhesive strategies. Eur J Oral Sci 117(4): 447-453.

22. Tjan AH, Grant BE, Dunn JR (1991) Microleakage of composite resin cores treated with various dentin bonding systems J Prosthet Dent 66(1): 24-29.
23. Mazzitelli C, Ferrari M, Toledano M (2008) Surface roughness analysis of fiber post conditioning process. J Dent Res 87(2): 186-190.

24. Monticelli F, Toledano M, Tay F (2006) A simple etching technique for improving the retention of fiber posts to resin composites. JOE 32(1): 44-47.

25. Menezes MS, Queiroz EC, Soares PV (2011) Fiber post etching with hydrogen peroxide: Effect of concentration and application time. JOE 37(3): 398-402.

26. Goracci C, Fabianelli A, Sadek FT, Papacchini F, Franklin R Tay, et al. (2005) The contribution of friction to the dislocation resistance of bonded fiber posts. Journal of Endodontics 31(8): 608-612.

27. Moraes AP, Sarkis Onofre R, Moraes RR, Cenci MS, Soares CJ, et al. (2015) Can Silanization Increase the Retention of Glass-fiber posts? A Systematic Review andMeta-analysis of In Vitro Studies. Operative Dentistry 40(6): 567-580. 